\title{
Advanced prototype using second harmonic generation (SHG) for pre-screening of conglomerates
}

\author{
A. Galland, V. Dureisseix, J. Mahieux, V. Dupray, H. Atmani and G. Coquerel \\ SMS UPRES EA3233, Université de Rouen \\ La2B - Centre Universitaire d'Evreux, 1 rue du 7ème Chasseur - BP 281 \\ F-27002 Evreux Cedex, France \\ gerard.coquerel@univ-rouen.fr
}

\begin{abstract}
:
Up to know, the enantiomers of component A (a chiral intermediate schematized in figure 1) have been separated by means of chiral chromatography. A less expensive method applicable to industrial production was requested. The resolution by preferential crystallization, which requires a stable conglomerate, could be one of the alternative routes. In this study, the screening of potential conglomerates was performed by using the Second Harmonic Generation (SHG). Among the 109 crystallization attempts with different counter ions and solvents, 51 crystalline salts were obtained; a single conglomerate-forming system has been detected (with sulfamic acid). Resolution by means of preferential crystallization has been achieved with this salt. This paper underlines the potential of SHG method as a pre high throughput technique for spotting chiral discrimination in the solid state.
\end{abstract}

\section{Keywords:}

Chiral discrimination, Second Harmonic Generation, stable conglomerate, preferential crystallization

\section{INTRODUCTION}

Chiral resolution can be performed by using chiral chromatography, chiral resolving agents (pasteurian method) but also by preferential crystallization for compounds crystallizing as conglomerates (ie. mixture of enantiopure crystals). One of the serious limitations to the application of preferential crystallization is that only $5 \%-10 \%$ of molecular compounds are conglomerates [1].

Various methods are commonly used to identify conglomerates (X-Ray Diffraction, IR spectroscopy, Raman spectroscopy...) but most of them are time consuming and require the pure enantiomer to be available.

Recently, the potential of Second Harmonic Generation (SHG) for conglomerate detection was investigated [2].

In Second Harmonic Generation (SHG) experiments, part of the incident light of wavelength $\lambda$ (frequency $\omega$ ) passing through a crystal is converted into light of wavelength $\lambda / 2$ (frequency $2 \omega$ ) [3-5]. The intensity of the SHG signal relies on the symmetry class to which the crystal belongs. Centrosymmetric space groups are SHG inactive and by contrast non centrosymmetric space groups are SHG positive. Consequently, as racemic compounds are known to crystallize predominantly in centrosymmetric space groups e.g. $\mathrm{P} 2{ }_{1} / \mathrm{c}$, Pbca and $\mathrm{P}-1$, they are not expected to exhibit any SHG activity. Conversely, conglomerates crystallize in a special category of non centrosymmetric space groups: the chiral space groups. Thus, they are expected to present a SHG activity. (From statistical data it appears that almost $95 \%$ of the conglomerates correspond to the following space groups: $\mathrm{P} 2{ }_{1}{ }_{1}{ }_{2}, \mathrm{P} 2{ }_{1}, \mathrm{C} 2$ or $\left.\mathrm{P} 1\right)$.

In reference 2, it was underlined that SHG can be used as a prescreening method for conglomerate detection and presents several advantages. Indeed, it requires only a few amount of material; it is also a fast (the answer is delivered instantaneously) and cheap method. Moreover, it does not require any test on the pure enantiomer. These benefits perfectly fit with industrial issues such as the chiral resolution of component $A$.

Indeed, Component $A$ is an intermediate in the synthesis of an active pharmaceutical ingredient. Only one of the enantiomer of component $A$ is desired for the synthesis. Unfortunately, the racemic mixture itself does not crystallize as a stable conglomerate. However, preferential crystallization can also be performed on accessible derivatives such as salts solvated or not crystallizing as a stable conglomerate.

With this aim in view, a screening of conglomerates via SHG effect was applied to $(+/-)$ component $A$ by means of salt formations with more than 60 acids in different solvents.

The general context of this work also fits with one of our objectives: improve the accuracy and prevent some drawbacks of the SHG method by increasing the number of studied molecules.

\section{EXPERIMENTAL SECTION}

\subsection{Preparation of salts}

(+/-) component A salts were obtained from acid-base reactions with the $1: 1$ stoichiometry by addition of an achiral acid and (+/-) component $A$ in different solvents (methanol, acetonitrile, methyl-tertiobutylether: MTBE hereafter).<smiles>[R1]c1c(N)ccc2c1CCC(N([R])C)CC2</smiles>

Figure 1: Developed formula of component $A$

Approximately $50 \mathrm{mg}$ of free base were used for every crystallization trial; different kinds of acids were used for this study (aliphatic carboxylic or sulfonic acids, aromatic

This is an Open Access article distributed under the terms of the Creative Commons Attribution-Noncommercial License (http://creativecommons.org/licenses/by-nc/3.0/), which permits unrestricted use, distribution, and reproduction in any noncommercial medium, provided the original work is properly cited. 
carboxylic acids, inorganic acids). First, the acid and base were mixed vigorously with few drops of solvent. Then, the vials were left to crystallize by slow evaporation (at room temperature) or crystallization was induced by ultra sounds or low temperature $\left(T=4^{\circ} \mathrm{C}\right)$.

\subsection{Second Harmonic Generation set-up}

Figure 2, shows the experimental set-up used for the SHG measurements. The laser is a Nd:YAG Q-switched laser (Quantel) operating at $1.06 \mu \mathrm{m}$. It delivers $360 \mathrm{~mJ}$ pulses of 5 ns duration at a repetition rate of $10 \mathrm{~Hz}$. The energy adjustment device is made up two polarizers $(P)$ and a halfwave plate $(\lambda / 2)$. It allows the incident energy to vary from 0 to circa $200 \mathrm{~mJ}$ per pulse. A RG1000 filter is situated after the energy adjustment device to removes light from laser flash lamps. The samples (powdered crystals confined between two microscope slides in sample holders of $8 \mathrm{~mm}$ in diameter and $1.6 \mathrm{~mm}$ long) were irradiated with $60 \mathrm{~mJ}$ pulses with a beam diameter of $4 \mathrm{~mm}$. The signal generated by the sample (diffused light) was collected into an optical fibre $(500 \mu \mathrm{m}$ of core diameter) and directed onto the entrance slit of a spectrometer (Ocean Optics). A boxcar integrator allowed an average spectrum (spectral range 250-700 nm with a resolution of $\pm 2 \mathrm{~nm}$ ) to be recorded over 1 second (10 pulses). Each spectrum was finally processed to extract the effective value of the SHG signal at $532 \mathrm{~nm}$.

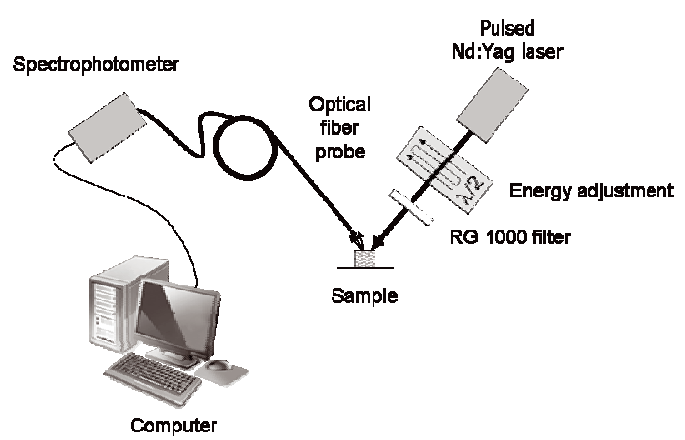

Figure 2 : Second harmonic generation set-up

\subsection{X-Ray Powder Diffraction}

XRPD analyses were achieved with a SIEMENS D5005 diffractometer (Bruker analytical X Ray Systems, Karlsruhe, Germany) using a Bragg Brentano geometry, in theta- theta reflection mode. The instrument is equipped with a X-Ray tube (copper anticathode, $40 \mathrm{kV}, 30 \mathrm{~mA}$, Ka1 radiation: 1.5406 $\AA$, Ka2 radiation: $1.5444 \AA$ ), a nickel filter and a scintillation detector. The diffraction patterns were collected by steps of $0.04^{\circ}$ (2-theta) over the angular range $3^{\circ}-30^{\circ}$, with a counting time of 4 sec per step.

\section{RESULTS}

\subsection{SHG measurements}

Among 109 crystallization trials (based on 69 acids in different solvents), only 51 crystalline materials were obtained and analyzed by means of SHG test. Five samples have shown a significant SHG activity (at least 2 times above the background noise): the sulfamic salt in methanol and in acetonitrile, the benzoic salt in MTBE, the 4-fluorobenzoic salt in MTBE, the 5-chlorosalicylic salt in MTBE and the anthranilic salt in MTBE.
The various acids used to obtain these 5 samples and the (+/-) component A were also submitted to SHG test to ensure that they were not responsible for the positive signal. Indeed, no SHG activity was observed.

To conclude on the conglomerate nature of SHG active racemic mixtures, a study of these samples by conventional methods such as a comparison between the XRPD patterns of the racemic salts and those of the corresponding enantiomeric salts were carried out (both XRPD patterns have to be exactly superimposable for a conglomerate).

\subsection{X- Ray Powder Diffraction analyses}

Among the 5 samples presenting SHG activity, only the XRPD patterns of the racemic sulfamic salt and the enantiomer sulfamic salt were found identical (figure 3 ). However, one can not conclude that the 4 other salts are not conglomerates. Indeed, in this study, the possibilities of polymorphism or efflorescent solvate were not investigated [2].

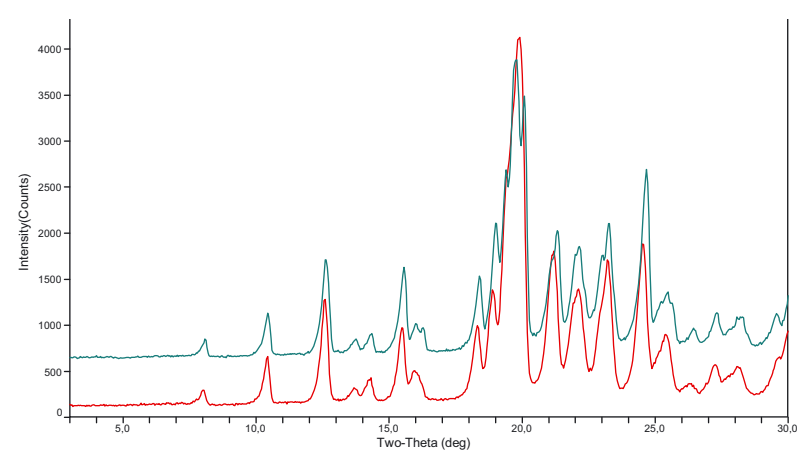

Figure 3: XRPD patterns of the racemic sulfamic salt (in red) and the enantiomeric salt (in green) (identical results whatever the solvent)

\subsection{Auto seeded polythermic programmed preferential crystallization (AS3PC) applied to the sulfamic salt}

The separation of enantiomers by preferential crystallization is possible only if the racemic mixture crystallizes as a conglomerate. Thus, to confirm the conglomerate nature of the sulfamic salt, auto seeded preferential crystallization (AS3PC) was applied. The first AS3PC attempts were performed at a very low concentration $(\mathrm{C}=2.2 \% \mathrm{w} / \mathrm{w})$ in a mixture $\mathrm{H}_{2} \mathrm{O} / \mathrm{IPA}(85 / 15) \mathrm{v} / \mathrm{v}$ due to a small amount of starting material available.

A total of $3 \mathrm{~g}$ of $(+/-)$ sulfamic salt were mixed with $297 \mathrm{mg}$ of pure (-) sulfamic salt (at the beginning of the process, a partial amount of the enantiomer in excess has to be present as a solid crystallized phase) in $133.6 \mathrm{~g}$ of mixture $\mathrm{H}_{2} \mathrm{O} /$ IPA. The suspension (initial enantiomeric excess equal to $9 \%$ ) was maintained at $47^{\circ} \mathrm{C}(\mathrm{Tb})$ for $30 \mathrm{~min}$ under stirring, and then quenched to $5^{\circ} \mathrm{C}$ (Tf). The stereoselective crystalli zation was monitored by polarimetry. Figure 4 shows the evolution of the rotatory power of the mother liquor versus time during the first batch operation. The inversion of the specific rotation testifies that the entrainment effect does exist.

Filtration was carried out after $95 \mathrm{~min}$ at $5^{\circ} \mathrm{C}$ and led to $626 \mathrm{mg}$ of crystals with an enantiomeric excess of $79 \%$. This corresponds to $494 \mathrm{mg}$ of pure enantiomer. The yield is poor but the monitoring of mother liquor necessitated several samplings that have induced significant losses of material. 


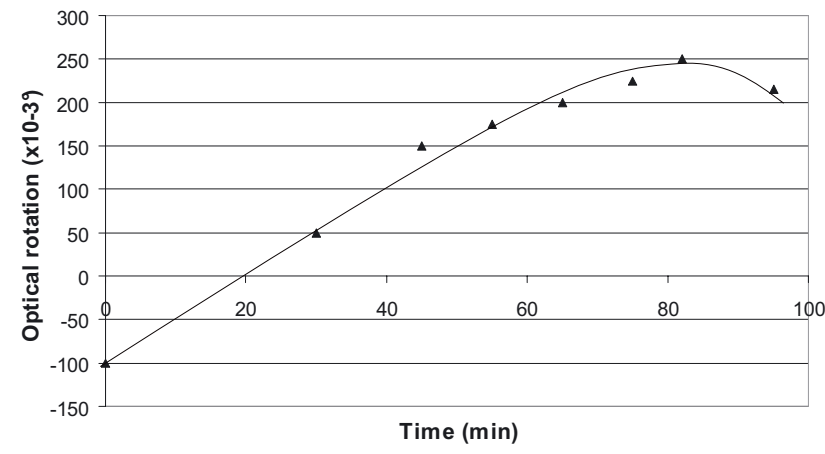

Figure 4: Polarimetric monitoring of the mother liquor during the run in mixture IPA/ $\mathrm{H}_{2} \mathrm{O}$

The entrainment effect confirms the conglomerate nature of the sulfamic salt. Moreover, these results are consistent with the XRPD analysis (superimposition of the XRPD patterns of the racemic sulfamic salt and the enantiomeric salt)

\section{DISCUSSION}

Second Harmonic Generation has been successfully used to spot 5 non centrosymmetric crystal lattices among 51 crystallized salts tested. In the subset of these 5 SHG positive derivatives, the sulfamic salt is a stable conglomerate because the first trials of preferential crystallization did show the entrainment effect.

Experiments are still in progress to conclude on the nature (conglomerate or non centrosymmetric racemic compound) of the 4 others samples that have generated a SHG activity. Several different situations can be contemplated:

- The racemic compound lattice can be non centrosymmetric and non chiral. That is to say the space group belongs to one of the following symmetry classes: $m, m m 2,-4,4 m m,-42 m, 3 m,-6$, $6 m m,-6 m 2,-43 m[2]$.

- The racemic mixture can crystallize as a metastable conglomerate (see F. Querniard et al. communication)

- The racemic mixture could have crystallized as a stable conglomerate and the pure enantiomer as a metastable polymorph or solvate (because the enantiomer available has not the same impurity profile as that of the racemic mixture) [6].

It should be mentioned that base $A$ is colored and the salts were also all colored: from pink to dark brown. This could have been an obstacle to the detection of the SHG effect. Fortunately, in that study the absorption of the green light $(532 \mathrm{~nm})$ was not strong enough to prevent the detection of the second harmonic beam.

\section{CONCLUSION}

This study demonstrates the ability of SHG tests to rapidly pre-select "good" candidates exhibiting chiral discrimination in the solid state, i.e. a subset of crystallized phases that includes conglomerates. In addition, it is worth noting that SHG technique is non destructive and requires a small quantity of racemic mixture only. Moreover, the availability of the pure enantiomer is not necessary.

\section{ACKNOWLEDGMENTS}

The authors thank Cephalon Inc. (West Chester PA) for its support.

\section{REFERENCES}

[1] Jacques, J.; Collet, A.; Wilen, S. H., 1994, Enantiomers, Racemates and Resolutions; Kriger: Malabar Florida, USA.

[2] Galland, A, Dupray, V., Berton, B , Morin, S., Sanselme, M., Atmani, H., Coquerel, G. , 2009, Spotting conglomerates by second harmonic generation, Crystal Growth and Design, 9, 2713-2718.

[3] Andrews, D.L., Allcock, P., Demidov, A.A., 1995, Theory of second harmonic generation in randomly oriented species, Chemical Physics, 190, 1-9.

[4] Strachan, C.J., Rades, T., Lee, C.J., 2005, Determination of the optical second harmonic response of pharmaceutical solid-solid mixtures, Optics and Lasers in Engineering, 43, 209-220.

[5] Timofeeva, T.V., Nestorov, V.N., Dolgushin, F.M., Zubavichus, Y.V., Goldshtein, J.T., Sammeth, D.M., Clarck, R.D., Penn, B., Antipin, M.Y., 2000, One-pot polymorphism of nonlinear optical materials. First example of organic polytypes, Crystal Engineering, 3, 263-288.

[6] Coquerel, G. Amabilino, D. 'The nanoscale aspect of chirality in crystal growth: structure and heterogeneous equilibria' in Chirality at the nanoscale, Chapter $10,305-348$, Wiley-VCH 2009, Ed Amabilino, D. 